NBER WORKING PAPER SERIES

\title{
PATENT DISCLOSURES AND STANDARD-SETTING
}

\author{
Josh Lerner \\ Haris Tabakovic \\ Jean Tirole \\ Working Paper 22768 \\ http://www.nber.org/papers/w22768 \\ NATIONAL BUREAU OF ECONOMIC RESEARCH \\ 1050 Massachusetts Avenue \\ Cambridge, MA 02138 \\ October 2016
}

This research was partially sponsored by the funding from the National Science Foundation (Grant no. 0830288), Toulouse Network for Information Technology, Harvard Business School's Division of Research, and European Research Council (Grants no. FP7/2007-2013-249429 and 669217). Josh Lerner is a member of the Toulouse Network on Information Technology, which receives support from Microsoft, and has done advisory work relating to corporate venturing with a number of technology firms. Haris Tabakovic is an associate at the Brattle Group, which provides economic, regulatory, and financial consulting services to various corporations, law firms, and governments. Jean Tirole is a member of IDEI, whose research received funding from Microsoft, Orange and Qualcomm, and of TSE, whose Digital Chair receives funding from Samsung and Orange. We would like to thank Mike Foley at Bluetooth SIG, William Geary at MPEGLA, Joseph Mueller at WilmerHale, Ruud Peters at Philips, Dirk Weiler at Nokia-Siemens Networks and the ETSI, and many others at Microsoft, Google and Qualcomm for helpful discussions related to patent-pooling and standard-setting processes. Participants in the Toulouse Network for Information Technology Annual Meeting provided useful comments. Duncan O'Brien, Paul Stavropoulos and Andrew Steen provided excellent research assistance. All errors are our own. The views expressed herein are those of the authors and do not necessarily reflect the views of the National Bureau of Economic Research.

At least one co-author has disclosed a financial relationship of potential relevance for this research. Further information is available online at http://www.nber.org/papers/w22768.ack

NBER working papers are circulated for discussion and comment purposes. They have not been peer-reviewed or been subject to the review by the NBER Board of Directors that accompanies official NBER publications.

(C) 2016 by Josh Lerner, Haris Tabakovic, and Jean Tirole. All rights reserved. Short sections of text, not to exceed two paragraphs, may be quoted without explicit permission provided that full credit, including $\odot$ notice, is given to the source. 
Patent Disclosures and Standard-Setting

Josh Lerner, Haris Tabakovic, and Jean Tirole

NBER Working Paper No. 22768

October 2016

JEL No. L24,O34

\section{ABSTRACT}

A key role of standard setting organizations (SSOs) is to aggregate information on relevant intellectual property (IP) claims before deciding on a standard. This article explores the firms' strategies in response to IP disclosure requirements-in particular, the choice between specific and generic disclosures of IP - and the optimal response by SSOs, including the royalty rate setting. We show that firms with a stronger downstream presence are more likely to opt for a generic disclosure, as are those with lower quality patents. We empirically examine patent disclosures made to seven large SSOs, and find results consistent with theoretical predictions.

Josh Lerner

Harvard Business School

Rock Center 214

Soldiers Field

Boston, MA 02163

and NBER

jlerner@hbs.edu

Haris Tabakovic

Harvard Business School

Cotting Hall

Soldiers Field Road

Boston, MA 02163

htabakovic@hbs.edu
Jean Tirole

Toulouse School of Economics

21 allée de Brienne - MF 529

31015 Toulouse Cedex 6

FRANCE

jean.tirole@tse-fr.eu 


\section{Introduction}

Technological standards are a central component of the modern network economy and can have significant welfare effects. As a consequence, mechanisms behind standard development and implementation represent a major policy concern. Most modern standards are created by consensus-driven standard-setting organizations (SSOs), and involve the voluntary participation and collaboration of many different entities: firms, government agencies, individuals, academic institutions and research laboratories. Their willingness to disclose and license standard-essential patents (SEPs) ${ }^{1}$ is crucial for standard implementation and its future success. SSOs play a pivotal role in this process by ensuring that concerns about ex-post hold-up are minimized through proper disclosure of SEPs and fair, reasonable and non-discriminatory (FRAND) licensing commitments made by patent owners.

The hold-up problems in standard-setting usually come in one of two flavors, the second of which motivates the exploration in this paper. In the first variant, ex-post hold-up can arise when patent owners strategically underdisclose their patents, so to avoid FRAND provisions. The case of Rambus is a prime example. $^{2}$ Rambus failed to disclose its existing DRAM related patents and patent applications during a standard-setting process at JEDEC SSO, and suspiciously amended some of its new patent applications to read on the standard more closely. This kicked off a series of lawsuits that plagued the DRAM industry for more than a decade and led to an indecisive outcome. ${ }^{3}$

In the second variant, a firm making an FRAND licensing commitment ex-ante can decide to capitalize on the vagueness of the term "reasonable" and attempt to extract unreasonably high royalty payments expost. A recent high-profile legal battle between Microsoft and Motorola illustrates this issue remarkably well. In this case, after being sued by Motorola for patent infringement, Microsoft countersued Motorola, accusing it of breaching its FRAND commitments made when disclosing SEPs to two different standards: IEEE 802.11 and ITU-T H.264. ${ }^{4}$ Microsoft has been widely using these standards in many of their flagship products, including videogame console Xbox 360 and Windows software, and accused Motorola of requesting unreasonable royalties for their SEPs. In a landmark 2013 decision, District Court Judge James L. Robard sided with Microsoft and reduced royalties due to Motorola to $\$ 1.8$ million per year from almost $\$ 4$ billion per year originally sought by them. In addition, the court ordered Motorola to pay $\$ 14.5$ million back to Microsoft in compensatory damages. ${ }^{5}$ However, the case did remain in court for more two years, and was

\footnotetext{
${ }^{1}$ In the course of the standardization process, there are usually many equally viable paths towards a technological solution, and SSOs often choose only one of them. In doing so, SSOs transform relevant patents into "standard-essential patents" and may allow their owners to command high royalties, even when other patents could have offered comparable value, had a different technological path been chosen.

${ }^{2}$ See Complaint, In re Rambus Inc., No. 9302 (F.T.C. June 18, 2002).

${ }^{3}$ http://en.wikipedia.org/wiki/Rambus\#Lawsuits.

${ }^{4}$ See Microsoft Corp. v. Motorola Inc., 696 F.3d 872 (9th Cir.2012).

${ }^{5}$ Awarded amount comprised legal defense costs, and breach-of-contract damages incurred by Microsoft in relocating its European
} 
very costly to resolve. Given the relative frequency of this behavior ${ }^{6}$, it may require a substantial change in patent disclosure policy and imposition of structured price commitments by patent owners to improve ex-post outcomes [Lerner and Tirole, 2015].

The type of patent disclosure made by organizations to SSOs varies. In some cases, these disclosures are very specific, listing actual patent award and/or application numbers potentially essential to the standard. In other cases, they are much broader, indicating only that the organization has potentially essential intellectual property (IP) and that any such IP will be made available on FRAND terms. The latter are known as generic patent disclosures or blanket disclosures.

This paper analyzes disclosure and selection mechanisms in standard-setting. First, we develop a model of functionality build-up by an SSO. During the standardization process, the SSO comes upon a potential functionality. Implementing this functionality may require acquiring a license to a commercial patent. If so, the patent may be minor, in the sense that there may be alternative routes to implementing the functionality that bypass the patent, or major, in which case a license is the sole path to implementation. Both minor and major innovations are socially useful, as they enable or at least speed up the incorporation of the functionality into the standard. The IP owner has an incentive to disclose so as to steer the technology toward his own solution, but he may be tempted to inflate the importance of his patent.

The SSO indeed does not know which patents are major or minor. To this purpose, it can require disclosure of essential patents, and then conduct its own investigation to confirm that the patent is a major one, or to find a substitute to the disclosed patent. This investigation is costly: it consumes engineering and legal resources and delays the standard's completion. In this respect, the model follows the tradition of costly-state-verification modeling [Townsend, 1979].

Generic and specific disclosures differ in several dimensions. The dimension captured in the model is that specific disclosures are meant to cover more important patents. We formalize this by making the realistic assumption that FRAND enforcement is more lenient with specific rather than with generic disclosures: the patent can fetch a higher royalty (we later investigate the foundations of such a policy). We thus view specific disclosures as claims to essentiality.

This framework allows us to investigate a number of empirically relevant questions: for example, how do FRAND requirements, the importance and urgency of the standard affect the incentive to disclose, the expediency of the standard-setting process, and the probability that minor patents be treated as major ones (i.e. are "standard essential" without being per se essential)? Among other predictions, we show that downstream presence makes IP owners more likely to make generic disclosures.

distribution center from Germany to Netherlands (to mitigate Motorola's initial injunction).

${ }^{6}$ For example, see Broadcom Corp. v. Qualcomm Inc., 501 F.3d 297, 310 (3d Cir. 2007.) 
We then evaluate patent disclosures made to seven large SSOs and find results consistent with theoretical predictions. We manually examine 10,258 patent disclosures made by 533 different entities to seven large SSOs through the end of 2012. This results in over 140,000 standard-eligible patents. Disclosed patent numbers are standardized, and all entity names are harmonized and mapped to their respective parent companies at the time each disclosure was made. When the probability of a patent being disclosed to an SSO via specific disclosure is regressed on a set of well-known patent quality measures and control variables, the coefficients are typically positive and significant, implying that higher quality patents are more likely to be disclosed in specific disclosures. When the probability of a firm using a specific disclosure is regressed on that firm's position in the value chain relative to the standard, a set of firm size measures and an interaction of the two, all interaction coefficients are negative and significant. This result is consistent with theoretical predictions that larger, downstream firms are less likely to disclose their patents in specific disclosures. Our specifications account for SSO, industry and year fixed effects. Both findings are consistent with theoretical predictions. At the same time, we realize that the interface of patent pools and standardization bodies are an extremely complex phenomenon, and that neither the model nor the empirics adequately captures the complexity of these interactions. It is our hope that this work will help illustrate the issues in this setting, and encourage future researchers.

Our study contributes to several strands of literature. It builds on the work of Farrell et al. [2007], Lemley and Shapiro [2013], and Lerner and Tirole [2014, 2015], among others, who show that simple FRAND patent licensing commitments create opportunities for strategic behavior of patent owners, only to induce outcomes that are ex-post inefficient. When it comes to patent disclosures, this paper shows that patent owners indeed behave strategically and that asymmetric information presents a problem that SSOs need to consistently grapple with. A related empirical study is Simcoe et al. [2009] who investigate the patent disclosure strategies to SSOs, link them to ex-post patent litigation, and show that they heterogeneously impact small and large-firms' incentives to litigate. In other related studies, Axelrod et al. [1995] examine firm choices to join standardization alliances, conditional on firm size and the presence of close competitors in those alliances, and Simcoe [2012] shows that strategic rent-seeking behavior of individual participants can lead to delays in standard-setting processes, especially when commercialization pressures are high.

The remainder of this paper is organized as follows: Section 2 discusses technical standards and firm disclosure strategies, and presents the economic model. Section 3 describes and summarizes the data, presents the hypotheses, empirical specifications and the results. Section 4 concludes the paper. 


\section{Technical Standards and Patent Disclosures}

\subsection{Background}

As a set of one or more technical specifications, a technical standard codifies a collection of common design rules for a product or a process. ${ }^{7}$

Standards have many flavors and can emerge in a multitude of ways. Some are developed privately by a single entity: a firm or government, for example. However, coordinated standard development through SSOs has been very common in recent decades. In the course of the standard-setting process, SSOs play several critical roles: they identify multiple paths towards a technological solution, they coordinate on one approach among conflicting alternatives and regulate the behavior of members.

One of the most important issues under the aegis of SSOs is ensuring that firms disclose relevant patents and agree not to price licenses to their patents too aggressively. Largely due to high coordination costs, sizable SSOs like the ETSI or the IEC usually require all of their members and participants to disclose any patents they believe may be standard-essential. This disclosure requirement serves multiple purposes, which are captured in the model: it directs the standard-setting process to take note of disclosed technologies, it forces disclosing parties to make licensing commitments (usually concurrent with the disclosure), it sends the signal to the market about the potential implementation costs down the line, and it provides valuable information for legal authorities in case of a dispute. These disclosure policies vary across different SSOs, and are usually difficult to change once set [Bekkers and Updegrove, 2012].

\subsection{Patent Disclosure Practices - Firms' Perspective}

We interviewed nearly one dozen practitioners regarding their organizations' attitudes and perspectives about the disclosure of IP to standards. These included lawyers and business development executives at companies specializing in software and telecommunications, SSO executives, and academic technology transfer officials.

The attitudes of the organizations towards disclosures of IP varied dramatically. We found a variety of explanations for undertaking generic or specific disclosures. Many of these are very consistent with our model, while others suggested a broader set of considerations we did not attempt to capture for brevity.

\footnotetext{
${ }^{7}$ See, for example, the definition for the purpose of the National Technology Transfer and Advancement Act (NTTAA): http://www.nist.gov/standardsgov/definestandards.cfm [last accessed: 06/10/2015].
} 


\subsubsection{Rationales for Generic Disclosure}

Many organizations are reportedly more likely to undertake generic disclosures if they are not seeking to license SEPs, but instead to make money off downstream products. One of the main reasons for undertaking generic disclosures was search cost containment: making a generic disclosure avoids the need for a patent search. Firms often found the process of sifting through patents to identify IP relevant to a standard to be an arduous and expensive task, which can consume thousands of hours of patent attorney time.

Since standards and patent applications evolve, sometimes dramatically, time considerations also lead firms to shy away from specific disclosures. An initial specific disclosure may not be relevant if the standard changes considerably during the formulation process. Similarly, patent applications may add or lose claims as they move through various patent offices, and may have a different scope when finally issued.

Specific disclosures can also lead to fears of being exposed to antitrust claims. If the firm makes a specific disclosure, there often is believed to be an implicit guarantee that all relevant IP has been disclosed. If the firm neglects to include all IP that could be relevant, even if the omission was unintentional, the firm may be vulnerable to antitrust claims if it seeks to enforce its patent portfolio. On the other hand, if the firm is perceived to disclose too many patents, there can also be accusations of delaying the standards process (as other firms seek to assess the disclosed patents) and potentially preemptively discouraging the effort entirely. For instance, to contain over-disclosures, the European Commission recommends that firms scrub lists of disclosed patents at the end of the standard-setting process, and include standard-relevant patents only.

\subsubsection{Rationales for Specific Disclosure}

Other firms prefer specific disclosures, particularly if they have valuable patents that are highly relevant for the standardization effort. Companies which are expecting to undertake licensing programs of SEPs very carefully track how different patents map to different standard functionalities. Thus, they are much more likely to have a good sense of which patents are relevant to a standardization effort, and to be capable of generating the information needed for a specific disclosure with less effort.

Specific disclosures help the firm with litigation and licensing negotiations if they are seeking to monetize SEPs. Even if the presence or absence of an SSO disclosure is not explicitly a criterion used in judicial decisions in patent infringement cases, the fact that the firm has undertaken such disclosure looks more favorable in court, particularly in a jury trial. In addition, many firms believe that the nature of the commitment to license with specific disclosures is more limited. In particular, with a specific disclosure, in many cases, the firm's commitment to license may only cover the listed patents. Generic disclosure 
ensures that all relevant patents will be made available on FRAND terms, which may not be the case for a specific disclosure when the standard evolves dramatically between the time of the disclosure and the promulgation of the final version.

Moreover, even if the SSOs do not explicitly require participants to engage in a patent search, there is often informal pressure to do so from other participants. Many SSO participants may prefer specific disclosures to ensure that patent search and examination costs are not passed down from one firm to all other firms in the group. In addition, they may prefer specific disclosures to avoid potential standard adoption delays, and obfuscation of user-relevant licensing information. Given the high frequency of repeated interaction among firms participating in the standard-setting processes, these informal mechanisms can be sufficiently powerful to complement formal SSO policies.

\subsubsection{SSO Role}

Of course, these decisions regarding disclosure may be affected by the rules of the SSOs themselves. In some cases, like the IEC, specific disclosures are strongly encouraged because they reduce search costs and enable SSOs to make more informed decisions about which patents are relevant and who owns them. The IEC, the ISO and the ITU common patent declaration policy highlights specific patent information as "desired but not required". ${ }^{8}$ Current disclosure policy at the ETSI, another large SSO, mandates that patent holders disclose specific patents in order to increase the transparency of the standard-setting process. ${ }^{9}$ Disclosure of essential patents and provision of licensing commitments are some of the main obligations of the ETSI members, and participation in various technical groups is conditioned on participating entities becoming members of the ETSI first.

\subsection{A model of standard setting disclosure}

The following model captures some features of the disclosure process. We refer to the discussion section for a broader perspective.

\footnotetext{
${ }^{8}$ Some standard-setting bodies and consortia operate under the ground rules that all relevant patents will be available under FRAND terms - or royalty-free ones-unless clearly indicated. Thus, firms must explicitly identify which patents are not covered by these rules, and in some cases, must explain how these patents are relevant to the standard (normally, there is no requirement for such an explanation). For example, see ITU/ISO/IEC, Guidelines for Implementation of the Common Patent Policy for ITU-T/ITU-R/ISO/IEC, Edition 3.0, June 26, 2015 (http:/ /www.iec.ch/members_experts/tools/patents/documents/ITU-T_ITUR_ISO_IEC_Common_Guidelines_2015-06-26.pdf, accessed May 12, 2016). The first version of the Guidelines for Implementation of the Common Patent Policy for ITU-T/ITU-R/ISO/IEC was published on March 1, 2007.

${ }^{9}$ Dirk Weiler (The ETSI Board Chairman), telephone conversation with authors, February 2015.
} 


\subsubsection{Patents}

A functionality, whose implementation requires some knowledge, raises the end-user's gross surplus ${ }^{10}$ from $V-e$ to $V$, and so the parameter $e$ measures the essentiality of the functionality. We will assume that this knowledge is covered by a patent, which its owner may be eager to monetize. Were an undominated open source solution be readily usable to implement the functionality, SSO participants (except the owner of a commercial alternative) would reveal its existence and the functionality would be adopted right away. Thus, the interesting case arises when the currently dominant solution is patented. We make the "technology push" assumption that the existence of a patent suggests some new application for this technology, and that the patent owner proposes the new functionality.

There are two types of patents:

- Essential/major patents (type $\mathrm{H}$ innovations) are depicted in this model by the assumption that there is a single route to implement the corresponding functionality, so the patent cannot be bypassed; actually, we assume that it cannot even be duplicated within the context of the standard setting process. As a consequence, unless an SSO participant comes up with the relevant IP during the SS process, the functionality will not be embedded in the standard as there might be no reasonable technical solution, in which case compliance with the standard is infeasible ${ }^{11}$.

- Minor patents (type $L$ innovations) are patents corresponding to an easier innovation, and for which there exists an alternative route. But in order to find this alternative route within the timeframe of standard setting, the SSO must build upon the knowledge embedded in the existing patent; put differently, the SSO cannot find a solution from scratch within the time frame. We further assume that bypass of the patent requires redefining the functionality in such a way that it is consistent with the alternative route; so bypass for simplicity is feasible at the SS stage, but not after the standard has been set.

Ex ante, the patent reading on the functionality has probability $\rho$ of being major and $1-\rho$ of being minor. Regardless of whether the patent is major or minor, looking for an alternate route (undertaking an "inspection") is costly in two ways: first, it delays the SS process, implying a discount factor $\delta<1$. Second, the SSO draws a random cost $c$ from smooth distribution $F(c)$ on $[0,+\infty)$; think of $c$ as representing the

\footnotetext{
${ }^{10}$ What we mean by "gross" is that the utility of users is equal to this gross surplus minus the royalty fee $p$. As we will see shortly, this gross surplus is already net of the prices charged by the downstream implementers.

${ }^{11}$ An alternative modeling choice would assume that it could be the case that there is a solution, but it will be owned by someone who does not participate in the process, creating a substantial hold-up concern.
} 
engineering and legal resources involved in the inspection. ${ }^{12}$ Thus if $p$ is the royalty licensing fee and if, as we later assume in the basic version of the model, the SSO internalizes the end-users' welfare, the SSO's payoff is $V-p$ if there is no inspection and $\delta(V-p)-c$ if there is one. The cost $c$ is drawn after the firm's disclosure choice (see timing below).

The firm wants to participate in the SS process so as to steer the standard towards its own IP. ${ }^{13}$ For simplicity, let us assume that firm $i$ knows whether its IP is essential or minor (thus $\rho$ is the probability assigned by the SSO to firm $i$ having an essential patent conditional on having a patent reading on the functionality).

\subsubsection{Players}

There are $n$ firms, indexed by $j$, that differ

- in their downstream presence (a standard is valued by firm $j$ at downstream profit $\theta_{j} \pi$, where $\Sigma_{j} \theta_{j}=1$ : $\theta_{j}$ is firm $j$ 's share of total profit of implementers, for instance $\theta_{j}=0$ for a pure IP player/non practicing entity, and $\pi$ is the total implementer profit),

- and in who owns this intellectual property: firm $i$ owns the intellectual property.

There is a single functionality, and (at most) one patent reading on this functionality, so market power in the upstream (IP) market is a potential issue.

If the functionality is adopted and the intellectual property has not been bypassed, the intellectual property will be able to command FRAND price $p_{H}<e$ in case of a specific disclosure and $p_{L}<p_{H}$ in case of a generic one. As we will see, it may not be the case that a minor patent fetches $p_{L}$. Namely, the owner of a minor patent may masquerade and pretend the patent is essential. He will then receive either licensing price $p_{H}$, or else 0 if his patent is bypassed. The two prices $p_{L}$ and $p_{H}$ are taken as exogenous at this stage (that's what a judge or jury would award in expectation if this were to go to court); later on, we will discuss the considerations involved in the court's setting of these two prices (optimal FRAND system).

Implementers are differentiated and compete in an oligopolistic fashion for end-users. We assume, for expositional simplicity only, that the royalties are fully passed through to end-users ${ }^{14}$ and that the IP owner's profit is equal to the royalty fee $p$ plus some downstream profit $\theta_{i} \pi$. An imperfect pass-through would not affect the qualitative conclusions, but it would complicate the analysis. Thus, the downstream prices are equal to $\left\{p_{j}^{*}+p\right\}_{j=1, \ldots, n}$ where $\left\{p_{j}^{*}\right\}$ would be the equilibrium prices if $i$ 's patent were to fall into

\footnotetext{
${ }^{12}$ The uncertainty about $c$ serves to create some uncertainty about what the SSO will do. Alternatively, we could have assumed that the SSO receives a private signal as to how likely it is that the patent is major.

${ }^{13}$ This might not be the case if the SSO were able to find a solution, but might not notice that it is covered by existing IP, giving rise to a potential hold-up.

${ }^{14}$ See Weyl and Fabinger [2013] for a general analysis of pass-through and incidence.
} 
the public domain. The gross surplus $V$ can thus be interpreted as $V_{0}-\Sigma_{j} p_{j}^{*}$, where $V_{0}$ is the gross surplus brought about by the standard.

Illustration. To obtain these two properties, suppose that total demand for the technology by end-users over the relevant price range is fixed at $X=1 .{ }^{15}$ Let $X_{j}\left(p_{1}, \ldots, p_{n}\right)$ denote the demand for implementer $j$, with $\Sigma_{j} X_{j}=1$. Because the relative attractiveness of offerings is invariant when all prices are raised by an equal amount and because total demand is constant, we assume that $X_{j}\left(p_{1}+p, \ldots, p_{n}+p\right)=X_{j}\left(p_{1}, \ldots, p_{n}\right)$. Suppose that firm $i$, the owner of the patent reading on the functionality, can levy royalty $p$ on the other implementers and that the marginal distribution cost is $d_{i}$. Then, firm $i$ maximizes over $p_{i}$

$$
\left(p_{i}-d_{i}\right) X_{i}\left(p_{i}, p_{-i}\right)+p\left[1-X_{i}\left(p_{i}, p_{-i}\right)\right]=\left(p_{i}-d_{i}-p\right) X_{i}\left(p_{i}, p_{-i}\right)+p,
$$

while a royalty-paying firm $j$ maximizes over $p_{j}$

$$
\left(p_{j}-d_{j}-p\right) X_{j}\left(p_{j}, p_{-j}\right)
$$

Note that firm $i$ de facto has opportunity cost $p$, and so the equilibrium prices are $p_{j}=p_{j}^{*}+p$ for all $j$, where $p_{j}^{*}$ is the equilibrium price when $p=0 .{ }^{16}$ Thus there is a $100 \%$ passthrough of the royalty to end-users (see the discussion in Section 2.3.7). And firm $i$ 's profit takes the form $\theta_{i} \pi+p$, where $\theta_{i} \pi \equiv\left(p_{i}^{*}-d_{i}\right) X_{i}\left(p_{i}^{*}, p_{-i}^{*}\right)$.

We must specify an objective function for the SSO; we will assume that the SSO stands for the interests of the end-users. As we will observe, it is straightforward to extend the analysis to broader objective functions. The SSO's objective function is $V-p$ if the $\mathrm{SSO}$ validates the functionality immediately, leading to price $p$ for the patent, and $\delta[V-\tilde{p}]-c$ if the SSO inspects, where $\tilde{p}=p$ if no bypass is found (major patent) and $\tilde{p}=0$ otherwise (minor patent).

\subsubsection{Timing}

The timing goes as follows:

1) The SSO comes upon the potential functionality, which brings incremental value $e>p_{H}>p_{L}$ if implemented. That is, the gross user surpluses are $V-e$ without the functionality and $V$ with it.

2) The IP owner proposes a solution and selects a generic or specific disclosure strategy.

\footnotetext{
${ }^{15}$ We assume that equilibrium prices are not so high that consumers no longer consume the goods.

${ }^{16}$ If the price game has multiple equilibria, we assume that the equilibrium selection is not affected by $p$, in the sense that $p$ shifts all prices one-for-one.
} 
3) The SSO knows that the IP solves the problem at hand, but does not know whether this is a major or a minor innovation, i.e. whether it can be bypassed. It learns $c$ and can either search for an alternative ("inspect", "try to bypass") or not. If it succeeds, the functionality is implemented without the users' having to pay royalties for this particular functionality. ${ }^{17}$

Essentiality inflation will refer to the propensity of the owner of a minor patent to declare its patent essential by making a specific disclosure.

A standard-essential patent, by opposition with a per-se essential (major) patent, will be defined as a minor patent that is declared specific and is made essential by the standard. ${ }^{18}$

We make the following assumptions (which reduce the number of cases to be considered without altering results qualitatively):

Assumption $1 p_{L} \leq(1-\delta) V$.

Assumption 1 says that $p_{L}$ is reasonable enough so that it is not worth for the SSO to try to bypass even if it knows that an alternative exists and $c=0$. This means that a generic disclosure will lead to immediate adoption of the functionality.

Assumption $2 p_{L}+\theta_{i} \pi \leq \delta\left(p_{H}+\theta_{i} \pi\right)$.

Assumption 2 means that the owner of a major innovation will never settle for $p_{L}$ even if a specific disclosure led to an inspection for sure.

We will let $\hat{\rho}$ denote the belief that the innovation is major conditionally on a specific disclosure (from Assumption 2, this belief is equal to 0 in case of a generic disclosure). If $y$ is the probability that a minor patent falls under a specific disclosure:

$$
\hat{\rho}=\frac{\rho}{\rho+(1-\rho) y} .
$$

$y$ thus covaries negatively with $\hat{\rho}$.

\subsubsection{Equilibrium}

Let us first solve for the SSO's behavior when the owner undertakes a specific disclosure. The SSO chooses not to inspect and to embed the functionality immediately into the standard if and only if:

$$
V-p_{H}>\delta\left[\hat{\rho}\left(V-p_{H}\right)+(1-\hat{\rho}) V\right]-c .
$$

\footnotetext{
${ }^{17}$ In this model, the absence of royalty will be the only "punishment" inflicted upon the owner of a minor patent who claims essentiality. In practice, courts may frown upon "over-disclosure". Due to SSO's rational inattention, disclosing hundreds or thousands of specific patents amounts to a generic disclosure. We leave it to future work to try to capture this notion in a multi-functionality extension of this model.

${ }^{18}$ See footnote 1.
} 
Let $c^{*}(\hat{\rho})$, a decreasing function, be defined on $[\rho, 1]$ by:

$$
V-p_{H}=\delta\left[\hat{\rho}\left(V-p_{H}\right)+(1-\hat{\rho}) V\right]-c^{*}(\hat{\rho}),
$$

if $(1-\delta) V \leq(1-\delta \hat{\rho}) p_{H}$ and $c^{*}(\rho)=0$ if $(1-\delta) V \geq(1-\delta \hat{\rho}) p_{H}$. Provided that $(1-\delta) V<(1-\delta \rho) p_{H}$, which we will assume, the equilibrium does not involve automatic rubberstamping (in particular $c^{*}(\rho)>0$ ). Were this condition violated, there would be only specific disclosures.

When a specific disclosure is made, the probability of inspection is thus

$$
x=x(\hat{\rho}) \equiv F\left(c^{*}(\hat{\rho})\right)
$$

Let us now turn to the disclosure decision. Note first that a separating outcome (in which the essential patents receive a specific disclosure and the minor ones a generic disclosure: $\hat{\rho}=1$ ) cannot be an equilibrium: otherwise the SSO would never try to bypass (since $c^{*}(1)=0$ ), as this would be doomed to fail. And so the owner of a minor patent would prefer to get $p_{H}$ instead of $p_{L}$ by claiming essentiality.

Like in standard "inspection games", the equilibrium must be in mixed strategy. This equilibrium will be defined by three parameters: the cutoff $c^{*}$ under which the SSO attempts to bypass the patent; the probability $x=F\left(c^{*}(\hat{\rho})\right)$ that the SSO tries to bypass; and the belief $\hat{\rho}$ that the firm has an essential patent.

We are thus led to consider two cases:

Non-informative disclosure. In this pooling equilibrium, there is systematic essentiality inflation: $y=1$ and $\hat{\rho}=\rho$. This equilibrium exists (and is the unique equilibrium) if

$$
p_{L}+\theta_{i} \pi \leq x(\rho) \delta \theta_{i} \pi+[1-x(\rho)]\left(p_{H}+\theta_{i} \pi\right) .
$$

Partly informative disclosure (semi-separating equilibrium). Suppose, next, that $p_{L}+\theta_{i} \pi>x(\rho) \delta \theta_{i} \pi+[1-$ $x(\rho)]\left(p_{H}+\theta_{i} \pi\right)$ and so a pooling equilibrium does not exist. In a partially informative disclosure equilibrium, the owner of a minor patent does not systematically claim essentiality, while the owner of an essential patent always does. The owner of a minor patent is indifferent between a generic and a specific disclosures:

$$
p_{L}+\theta_{i} \pi=x(\hat{\rho}) \delta \theta_{i} \pi+[1-x(\hat{\rho})]\left(p_{H}+\theta_{i} \pi\right)
$$

where

$$
x(\hat{\rho})=F\left(c^{*}(\hat{\rho})\right)
$$


Combining (1) and (2) yields.

$$
p_{H}-p_{L}=x(\hat{\rho})\left[(1-\delta) \theta_{i} \pi+p_{H}\right]
$$

The LHS of (3) is the financial gain in the absence of inspection. The RHS includes the delay cost, $(1-\delta) \theta_{i} \pi$, plus the loss of royalty $p_{H}$, if there is an inspection, which occurs with probability $x(\hat{\rho})$.

Proposition 1 (equilibrium disclosure) The equilibrium of the disclosure game is unique. Comparative statics are given by:

An increase in $p_{L}$, a decrease in $p_{H}$, an increase in the IP owner's downstream presence (an increase in $\theta_{i} \pi$ ), an increase in the urgency of the standard (a decrease in $\delta$ ) all lower the fraction of false essentiality claims ( $\hat{\rho}$ increases, $y$ decreases) and hastens the SS process ( $x$ decreases). An increase in the value of the standard to users ( $V$ increases) increases the frequency of false essentiality claims, but does not affect the speed of the SS process. ${ }^{19}$

In particular, a firm with a stronger downstream presence is more likely to go for a generic disclosure and is also treated with less suspicion by the SSO. And generic disclosures correspond on average to lower quality patents.

Alternative objective function for the SSO. Suppose more generally that the SSO cares not only about the end-users, but also about the implementers and the IP owner. Let the weights put on the three groups be 1, $\alpha$ and $\beta<1$, respectively (so far we had $\alpha=\beta=0$ ). The SSO's objective can then be written as:

$$
(V-p)+\alpha\left[\Sigma_{j \neq i}\left(p_{j}^{*}-d_{j}\right) X_{j}\left(p_{j}^{*}, p_{-j}^{*}\right)\right]+\beta\left[\left(p_{i}^{*}-d_{i}\right) X_{i}\left(p_{i}^{*}, p_{-i}^{*}\right)+p\right]
$$

It is thus proportional to

$$
\hat{V}-p
$$

where

$$
\hat{V} \equiv \frac{V+\left[\alpha\left(1-\theta_{i}\right)+\beta \theta_{i}\right] \pi}{1-\beta}>V .
$$

Applying Proposition 1, we see that the SSO's putting weight on implementers and IP owners encourages false essentiality claims, but overall does not affect the speed of the SS process. $V$.

\footnotetext{
${ }^{19}$ The probability of delay is $[\rho+(1-\rho) y] F\left(c^{*}(\hat{\rho})\right)=\frac{\rho F\left(c^{*}(\hat{\rho})\right.}{\hat{\rho}}$. Note that $\hat{\rho}$ is determined by (2) and (3), independently of the value of
} 


\subsubsection{Optimal FRAND royalties}

In this model, $p_{H}$ and $p_{L}$ perform three functions. They serve to encourage the creation of innovations, without which the functionality might not be embedded into the standard; they determine the end-users' cost of technology implementation; and finally they affect disclosure behavior. The first two effects depict the usual trade-off between innovation and market power. The third one is a novel one: it calls for lowering the difference $p_{H}-p_{L}$ so as to improve participants' behavior and economize on delay and inspection costs.

To make progress on this issue, we must describe the R\&D process prior to standard setting. We take a simple R\&D technology so as to clearly highlight the benchmark incentives in the absence of strategic disclosure. Namely, we assume that the minor and major patents involve R\&D costs $i_{L}$ and $i_{H}$ respectively, where $i_{L}<i_{H}$. These investments costs are a priori unrelated to the parameters $(c, \delta)$ that characterize the inspection process; for, this process builds on the shoulders of the earlier innovation. The correlation between the difficulty of the initial discovery and that of bypassing it captures the idea that some pieces of a technology are more complex than others.

We will focus on the case in which society wants both types of innovation to occur (otherwise a single royalty rate would be set: $p=i_{L}$ if only $L$ were to be produced ${ }^{20}$ ). This gives us incentive constraints:

$$
p_{k} \geq i_{k} \quad \text { for } \quad k \in\{L, H\} \text {. }
$$

The end-users' welfare can be written as: ${ }^{21}$

$$
\begin{aligned}
W\left(y, p_{H}, p_{L}\right) & \equiv(1-\rho)(1-y)\left(V-p_{L}\right) \\
& +(1-\rho) y\left[\int_{0}^{c^{*}(\hat{\rho})}(\delta V-c) d F(c)+\int_{c^{*}(\hat{\rho})}^{\infty}\left(V-p_{H}\right) d F(c)\right] \\
& +\rho\left[\int_{0}^{c^{*}(\hat{\rho})}\left(\delta V-c-\delta p_{H}\right) d F(c)+\int_{c^{*}(\hat{\rho})}^{\infty}\left(V-p_{H}\right) d F(c)\right],
\end{aligned}
$$

where

$$
\hat{\rho}=\frac{\rho}{\rho+(1-\rho) y} \text { and } F\left(c^{*}\left(\frac{\rho}{\rho+(1-\rho) y}\right)\right) \equiv \frac{p_{H}-p_{L}}{(1-\delta) \theta_{i} \pi+p_{H}} .
$$

Welfare $W$ is decreasing in $p_{L}$ and $p_{H}$, and, from Assumption 1, in $y$ as well. Because $y$ is increasing in

\footnotetext{
${ }^{20}$ It cannot be the case that only $H$ is produced. Then, there would be no inspection, and the $L$ innovation would make profit $p_{H}-i_{L} \geq i_{H}-i_{L}>0$, a contradiction. We ignore cases in which the innovations are produced stochastically.

${ }^{21}$ We here take the point of view that the inspection cost $c$ is borne by users, which is consistent with our assumption that the SSO represents the end-users' interests. Alternative assumptions concerning the incidence of $c$ would not alter the analysis much.
} 
$p_{H}$,

$$
\frac{d W}{d p_{H}}=\frac{\partial W}{\partial y} \frac{\partial y}{\partial p_{H}}+\frac{\partial W}{\partial p_{H}}<0
$$

and so

$$
p_{H}=i_{H}
$$

Next, $p_{L}$ is either equal to $i_{L}$ (corner solution) or is given by the following first-order condition (using the optimality of $c^{*}(\tilde{\rho})$ and the envelope theorem):

$$
\left[\int_{0}^{c^{*}(\hat{\rho})}\left[c+(1-\delta) V-p_{L}\right] d F(c)+\left[1-F\left(c^{*}(\hat{\rho})\right)\right]\left[p_{H}-p_{L}\right]\right]\left[-\frac{\partial y}{\partial p_{L}}\right]=1-y
$$

where $\partial y / \partial p_{L}$ is given implicitly by (4).

Proposition 2 The optimal FRAND system either involves a single price ( $p_{L}=p_{H}$, and thus makes no distinction between generic and specific disclosures) or two prices $p_{L} \geq i_{L}$ and $p_{H}=i_{H}$. Reducing essentiality inflation requires compressing the range of rewards $p_{H}-p_{L}$.

\subsubsection{Extension: Portfolio Search}

We can extend the model by introducing a cost $\gamma>0$ of searching in one's patent portfolio to see if one has a relevant patent. Let $\beta$ denote the probability of finding that one's patent covers a desirable functionality. The expected cost of "useful" search is therefore $\frac{\gamma}{\beta}$. Consistent with our previous assumptions, we can assume that the functionality is not embedded into the standard if there has not been a search. We also assume that the IP owner $i$ knows only the fraction of high-quality patents in his portfolio, and thus not whether the relevant one will have quality $H$ or $L$ (this assumption is not essential). The probability of discovering a major innovation conditional on a successful search is $\rho .^{22}$

One can generalize the analysis and show the following: an increase in downstream presence ceteris paribus (in particular, fixing the average quality of the patent portfolio) reduces the IP owner's probability of search through the patent portfolio. The reason for this is that the motivation for searching is the potential collection of royalties (socially, there is also the benefit for the users of an additional functionality, but this is not internalized by the IP owner). But claiming IP delays the process as analyzed above (the disclosure game is the same as above, where $\rho$ is now the probability of $H$ quality conditional on the search having been performed). Because a firm with a strong downstream presence particularly dislikes delays, such a

\footnotetext{
${ }^{22}$ The search is non-directed here. Directed search (in which the IP owner can affect the relative probabilities of discovering major and minor innovations in his portfolio) would lead, we conjecture, pure IP players to search more for major innovations (relative to minor ones) than firms with a strong downstream presence. Thus the direction of search, and not only its intensity, depends on downstream presence.
} 
firm will conduct fewer searches.

\subsubsection{Discussion}

This modeling is an incomplete first foray into the dynamics of disclosure and functionality inclusion. The theoretical model does not capture the richness of the standard setting process. While its two key conclusions - specific disclosures correspond to higher-quality patents and downstream firms are more likely to go for generic disclosures - seem robust, a refined description of how functionalities are included into a standard would be desirable. We can hypothesize that, roughly speaking, the inclusion of new functionalities can follow either a technology-push or a market- (here, SSO-) pull process.

The technology-push scenario corresponds to the situation in which the existence of a patent suggests a new functionality. This is the situation that is captured in the model. The originator of the new functionality through this channel is likely to be the patent owner, especially if the latter has chosen a generic disclosure: with a specific disclosure, it is easier for other SSO members to conceive of a use for the patent, even though the owner, incentivized by the prospect of collecting royalties, will always have more incentives than the other SSO members to look for a new functionality making use of the patent. Relative to the model, the possibility that other SSO members build on the specifically disclosed patents adds an incentive for the owner to make a specific disclosure, which enlists other members in the search for applications of the patent; but this would not qualitatively affect our two main results.

The market-pull view of inclusion of functionalities depicts the SSO thinking of a new functionality and, before including it into the standard, wondering how it can be implemented. This view may well explain why some SSOs are so keen to encourage their members to make specific disclosures (whereas in the model developed above, ignoring the ex-ante incentive to innovate treated in Section 2.3.5, the SSO ex post prefers generic disclosures). SSO members may search for a way to implement the desired functionality, only to discover that the solution is actually covered by a patent disclosed only in a generic fashion, and therefore not that transparent. This "hold up" argument would reinforce the case for discriminating royalties between specific and generic disclosures. Higher royalties for specifically disclosed patents then would reward not only the higher quality of such patents (an equilibrium property captured by our model), but also the prevention of free riding in the search process by the patent owner.

Note that in both the technology-push and the market-pull interpretations, we suggest that pure implementers (i.e., non-patent owners) might search for either uses of the patent or for implementations of an envisioned functionality. One might object that this conflicts with the modeling assumption that both surpluses and royalties are passed through to final users, so implementers are not impacted by the 
existence of a new functionality and by the level of royalties. (This is why we assumed that the SSO stands for the interests of end-users rather than for those of the implementers.) As a result of this assumption, the patent owner is the only party having an incentive to add the functionality.

However, a minor change to the model breaks this indifference and provides an incentive for pure implementers both to search for new functionalities and to object to high royalties. Suppose that a) endusers draw a payoff $\zeta$ from an outside option from some distribution $G(\zeta)$ in the population of end-users, and then decide whether to go for the outside option or for the technology certified by the SSO; and b) after picking the technology, they learn their preferences among implementers. The model is then the same as that described in Section 2.3.22 , except that an additional functionality or a lower royalty has a market-expansion effect. So even pure implementers have an incentive to add functionalities and to lower royalty rates.

As stated above, our model is only a first step toward understanding some of the many features of disclosure strategies. We leave it to future research to come up with a more refined view.

\subsection{Model Testing}

We perform an empirical analysis to examine two of the key features of Proposition 1.

First, we examine the relationship between patent quality and disclosure type. As we saw from the theory, disclosure type is likely to be correlated with patent quality. Hence, our first hypothesis is the following:

Hypothesis 1 Conditional on being disclosed to SSOs, higher-quality patents are more likely to be disclosed in a specific disclosure.

Next, we examine the relationship between the downstream presence and disclosure behavior. For firms with significant downstream presence (a large $\theta_{i} \pi$ ), the downside of potentially low royalties is offset by the upside of rapid technology diffusion, favorable to the firm's downstream operations. This logic leads us to our second hypothesis:

Hypothesis 2 Conditional on participating in standard-setting efforts, large downstream firms are more likely to make a generic disclosure.

\footnotetext{
${ }^{23}$ With a mass of end-users given by $G\left(V_{0}-\sum_{j} p_{j}^{*}-p\right)$.
} 


\section{Empirical Analysis}

\subsection{Data Sources}

Our analysis is based on a set of patent disclosures made through the end of 2012 to seven large, modern SSOs:

1. The American National Standards Institute (ANSI), an SSO overseeing the development of voluntary consensus standards for products, services, processes, systems, and personnel in the United States covering the wide range of industries. These include acoustical devices, construction equipment, dairy and livestock production, energy distribution, and many more. The ANSI also coordinates United States standards with international standards and serves as official representative of United States to the two major international standards organizations, the International Organization for Standardization (ISO), and the International Electrotechnical Commission (IEC).

2. The Advanced Television Systems Committee (ATSC), an SSO responsible for development of voluntary standards for digital television. The ATSC member organizations represent the broadcast, broadcast equipment, motion picture, consumer electronics, computer, cable, satellite, and semiconductor industries. The ATSC is working to coordinate television standards among different communications media focusing on digital television, interactive systems, and broadband multimedia communications.

3. The European Telecommunications Standards Institute (ETSI), an SSO operating primarily in the telecommunications industry, and covering both equipment makers and network providers. The ETSI is responsible for standardization of Information and Communication Technologies (ICT) within Europe. These technologies include telecommunications, broadcasting and related areas such as intelligent transportation and medical electronics.

4. The International Electrotechnical Comission (IEC), an SSO that creates and publishes international standards for all electrical, electronic and related technologies: anything from electromagnetics, electrical power and home appliances to semiconductors, fiber optics and nanotechnology.

5. The Institute of Electrical and Electronics Engineers (IEEE), an SSO focused on developing global standards in a wide range of industries covering power and energy, biomedical, IT, telecommunications, transportation, nanotechnology and many more.

6. The International Organization for Standardization (ISO), the world's largest developer of voluntary international standards covering a large variety of technologies and industries: from food safety and computers to energy, agriculture and healthcare. 
7. The International Telecommunication Union (ITU), a specialized United Nations agency responsible for information and communication technologies. The ITU allocates global radio spectrum and satellite orbits, develops the technical standards that ensure interconnection of networks and technologies in the global information and communication technology sector.

Our analysis starts with an identification of all standards developed by these seven SSOs. For every standard in our sample, we then identify all specifically disclosed United States (US) patents and patent owners, as well as all entities making generic patent disclosures. Identification of patent disclosures made to SSOs is a very tedious and time consuming task. While some SSOs—such as the ETSI, for example-do provide easily downloadable, comprehensive databases of patent disclosures, many others do not. And even in those cases where databases are readily available, patent number formats vary significantly and patent numbers are sometimes incomplete. In those cases where comprehensive databases were not readily available-like the IEC, for example-we sifted through scanned copies of disclosure letters and other documents to analyze patent disclosures, and manually extracted granted patent and patent application numbers. After extraction, we standardized formats of all disclosed patent numbers and harmonized names of all entities disclosing them, to be able to merge patent disclosure data with entity-specific financial and United States Patent and Trademark Office (USPTO) patent data. ${ }^{24,25}$

Since generic declaration letters do not list any specific patents, but rather provide a general statement of the type "we believe that we have patents relevant to the implementation of standard X" type, we must identify all patents that could potentially be disclosed via such statement. To accomplish this, we first build patent portfolios for all 353 entities making generic disclosures to standards in our sample. Assembling patent portfolios is a difficult task. Numerous variants of patent-seeking institution names appear in USPTO records. These are caused by either the variation in patent-prosecuting law firms or by human error and incorrectly spelled names. In addition, subsidiary and parent companies often appear as patent assignees completely independent of one another. For example, we could have patent A assigned to Philips North America, patent B assigned to Philips Healthcare, and patent C assigned to Philips Corporation. Since Philips North America and Philips Healthcare are both subsidiaries of Philips Corporation, all

\footnotetext{
${ }^{24}$ Some public databases of multiple-SSO patent disclosures do exist, however at the time we conducted this research, we found their time coverage to be inadequate. For example, while the recently updated version of SSO disclosure database maintained by Bekkers et al. [2012] covers disclosures to 13 SSOs through 2011, when we conducted our study it covered disclosures only through 2008. Our dataset covers disclosures through the end of 2012.

${ }^{25}$ While there are many international patents in our sample of disclosed patents, our analysis focuses on the US patents mainly because of the large size of downstream US markets and the "duty of candor" - a duty to disclose to USPTO all information material to patentability, or potentially deem the patent unenforcable. The large size of the downstream US markets leads us to believe that our results closely mirror the results one would find if the international patents were to be included. In addition, the USPTO "duty of candor" requirement is one of the most stringent, without its equivalent counterpart in other parts of the world like Europe, for example. As a consequence, all citation-based patent quality measures calculated over the set of the US patents should be more representative of the true patent quality than if calculated over the set of international patents.
} 
three patents should be grouped together as a part of Philips Corporation patent portfolio. ${ }^{26}$ We use a set of special features available in Thomson Innovation database to aggregate patent portfolios more accurately than the raw USPTO patent records would allow us to do. We use the browse feature in Thomson Innovation Assignee/Applicant search field to identify all possible assignee name variations. This feature is used together with a unique 4-letter Assignee Codes available in Thomson Innovation to identify one of approximately 22,300 patenting organizations worldwide and map them to all subsidiaries listed in Thomson database. Similarly to what we do with patents, we also aggregate all patent disclosures on a parent company level. This enables us to count and aggregate U.S. patents and patent applications wherever a firm or its subsidiary appears as an assignee or applicant on the patent record. Using this approach, we are able to identify almost 300,000 U.S. patents associated with 353 entities. Mergers and acquisitions, as well as company name changes are tracked over time, and mapped to the patent disclosure date to ensure the most accurate mapping. Table 1 shows the overall numbers of disclosed patents and standards by disclosure type covered in our dataset.

\section{[Table 1 about here.]}

Since we want to limit our patent sample only to those patents relevant to standards in question, we use patent International Patent Classification (IPC) technology codes to accomplish this. First, we use specifically disclosed patents to build a list of all primary IPC codes associated with every standard in the specifically disclosed patent sample. Next, we compare these lists with IPC codes assigned to generically disclosed patent portfolios. All generically disclosed patents having one or more standard-relevant IPC codes are deemed as standard-eligible. All other patents are dropped.

This process results in a dataset covering 1,589 standards. This dataset has 7,475 specific patent-standard disclosures from 313 different entities and 2,498 generic declaration letters covering 108,019 standard-eligible patents belonging to 197 different entities. Table 2 summarizes numbers of disclosed patents by disclosure type and SSO, including only standard-eligible patents as defined above.

[Table 2 about here.]

We obtain additional information about firms disclosing the patents to SSOs from the Standard \& Poor's Capital IQ and Compustat databases. These databases integrate financial and operational information on thousands of companies worldwide. We use Capital IQ's name-matching feature to match patent owner names to standardized entity names. We then assign a unique identifier to each entity in our sample and map it to the parent company. If we have separate disclosures from Philips North America and Philips

\footnotetext{
${ }^{26}$ The NBER patent dataset corrects this problem (at least partially), but since it does not cover US patents issued after 2006, we cannot use it [Hall et al., 2002].
} 
Healthcare, we map both of these companies to their ultimate parent-Philips Corporation. We use Capital IQ to obtain time series data on firm size, revenue and earnings, R\&D spending, capital expenditures, primary industry, age, and subsidiary-parent relationships. Since firms change their activities and industries over time, we also use S\&P Compustat to get historical firm segment information encompassing product and geographical industry segment data.

To test whether higher quality patents are more likely to be disclosed in specific disclosures, we use specifically disclosed patents to further circumscribe a technology space for each individual standard, and ensure that generically disclosed patents belong to the same space. This procedure reduces sample variability, and eliminates patents that are "technically" disclosed in generic disclosures, but have no real technical relevance for the standard.

We first create a list of all 6-digit IPC codes belonging to specifically disclosed patents for each individual standard. Next, we match the list of these standard-specific IPC codes to IPC codes belonging to generically disclosed patents for that same standard. For every standard in the sample we examine, we drop all generically disclosed patents which have no IPC codes in common with that standard's IPC code list. We also drop all standards which have only generic or only specific disclosures. The resulting sample contains only those standards which have both specifically and generically disclosed patents. On a patent level, we keep all specifically disclosed patents, and only those generically disclosed patents which have at least one IPC code in common with a list of IPC codes belonging to the standard they were disclosed to. This final sample consists of 59,221 generic and 5,453 specific patents.

\subsection{Disclosure Preferences and Patent Value}

\subsubsection{Variables}

To measure the economic value of disclosed patents, their technological importance and subsequent technological impact, we use a set of literature-based patent quality indicators:

1. Number of Forward Citations is associated with the technological importance and overall patent quality [Trajtenberg, 1990]. The number of forward citations is the number of times a patent document is cited in subsequent patents. We correct all forward citation counts for truncation on a 3-digit US patent class and cohort-year basis [Hall et al., 2002].

2. Patent Scope measures the technological breadth of patents by accounting for the number of International Patent Classification (IPC) technology classes each patent is assigned to. Patent scope was shown to have a significant impact on firm valuation: broader patent scope translates to higher firm 
valuation [Lerner, 1994]. For a patent $i$, the patent scope is calculated as:

$$
\text { Scope }_{i}=(\text { Number of } 4-\text { digit IPC codes })_{i}
$$

3. Number of Claims determine the boundary of technology exclusion rights described in the patent and are associated with technological and economic value of inventions [Lanjouw and Schankerman, 2001, 2004].

4. Patent Originality measures the technological breadth of patent references. Low originality score implies that a patent's backward citation set is technologically narrow (a small and focused number of technology classes), while the high originality score implies that backward citations belong to a larger and much broader set of technology classes [Trajtenberg et al., 1997, Hall and Trajtenberg, 2004]. The measure of patent originality is calculated using 4-digit IPC classes for all identified backward patent citations as:

$$
\text { Originality }_{i}=1-\sum_{j=1}^{N_{i}} O S_{i j}^{2}
$$

where $O S_{i j}^{2}$ is a share of patent $i$ 's citations coming from a patent class $j$ out of set of $N_{i}$ patent classes belonging to a set of all identified patent references cited by patent $i$. Originality is calculated using all the references retrieved from Thomson Innovation database.

5. Number of Patent References (Backward Citations) was shown to be positively correlated with the patent value [Harhoff et al., 2003]. The number of patent references is the number of other patent documents (including patent applications and self-citations) cited in the patent.

6. Number of Non-Patent References (Backward Citations) is correlated with more significant knowledge content [Cassiman et al., 2008]. The number of non-patent references such as scientific journals and books is also associated with higher patent quality and approval rates [Branstetter and Ogura, 2005].

7. Patent Family Size is an indicator of the economic value of patent rights. Patent family size is measured as the number of different patent jurisdictions (nations) in which patent protection was sought, excluding the European Patent Office (EPO) and the World Intellectual Property Office (WIPO). ${ }^{27}$ The size of the patent family is highly correlated with the patent "lifetime", i.e. the time from the initial patent application to patent expiration or assignee's decision not to renew the patent [Putnam, 1996, Lanjouw et al., 1998]. In addition, large patent families have been shown to be more valuable [Harhoff et al., 2003].

\footnotetext{
${ }^{27} \mathrm{EPO}$ and WIPO do not issue European or World patents, but rather serve as conduits to the various national patent offices.
} 
Summary statistics are given in Table 3.

[Table 3 about here.]

\subsubsection{Specification}

We use logit regressions to test if higher quality patents are more likely to be disclosed in specific disclosures:

$$
\operatorname{Pr}\left(\operatorname{Spec}_{i, b, t}=1\right)=F\left(\alpha+\beta \times \text { Patent Quality } i+\text { Year }_{t}+S S O_{b}+\epsilon_{i, s, t}\right)
$$

where

$$
F(z)=\frac{e^{z}}{\left(1+e^{z}\right)}
$$

In this specification, the dependent variable $S_{p e c} c_{i, b, t}$ is a dummy equal to 1 if a patent $i$ was disclosed in a specific disclosure to SSO $b$ in a year $t$. Patent $Q$ uality ${ }_{i}$ is the patent quality measure, whose construction is discussed in detail below. Year $m$ is a year fixed effect and $S S O_{b}$ is SSO fixed effect. We are particularly interested in the sign of the $\beta$ coefficient on the patent quality measure, and expect it to be positive.

In this particular case, we aggregate disclosures on SSO level (rather than the standard itself) for two reasons. First, our interviewees have indicated SSO-specific disclosure policies to be a major driver of how and what firms disclose. Second, because multiple patents are disclosed to many standards within and across SSOs, aggregating disclosures on the standard level would lead to many duplicate observations, and it would not be entirely appropriate to control for standard-level fixed effects. Since there are still many patents disclosed to multiple standards within SSOs, to make sure we are not overstating the significance of our results, we perform a simple degree-of-freedom correction and create a dummy for each year and SSO and average over them before running the regressions. Thus, our unit of observation is patent-SSO-year triplet. $^{28}$ This reduces the number of observations to 63,598 .

\subsubsection{Results}

Table 4 reports the results, and shows that higher quality patents are more likely to be specifically disclosed to SSOs. Each specification in the table accounts includes results with and without SSO and year fixed effects, and allows for heteroscedastic standard errors. The binary dependent variable is coded as one if the patent is disclosed in a specific disclosure, and zero otherwise.

Results for citation-based patent quality measures are shown in Panel A. This includes truncationcorrected forward citations, patent references and non-patent references. Columns (1)-(3) report estimates

\footnotetext{
${ }^{28}$ Since the two sets of specifically and generically disclosed patents are mutually exclusive on the SSO level, performing this correction does not change the binary nature of our dependent variable.
} 
for the count of truncation-corrected forward citations as the independent variable. The magnitudes of estimated coefficients range between statistically insignificant 0.0021 (without fixed effects), to $1 \%$ significant 0.093 (with fixed effects). We interpret these results as a 0.093 increase in log-odds of the patent being disclosed in a specific disclosure for every additional truncation-corrected forward citation it acquires. Columns (4)-(6) report estimates for the count of patent references as the independent variable. In this case, magnitudes of estimated coefficients range between 0.0111 (without fixed effects), to 0.0088 (with fixed effects). All coefficients in Columns (4)-(6) are significant at the $1 \%$ level. We interpret these results as a 0.0088 increase in log-odds of the patent being disclosed in a specific disclosure for every additional patent it cites. Columns (7)-(9) report estimates for the count of non-patent references as the independent variable. The magnitudes of estimated coefficients range between 0.0188 (without fixed effects), to 0.0172 (with fixed effects). All coefficients in Columns (7)-(9) are significant at the 1\% level. We interpret these results as a 0.0172 increase in log-odds of the patent being disclosed in a specific disclosure for every additional non-patent document it cites.

Panel B shows results for additional patent measures including patent scope, number of claims, patent originality and INPADOC patent family size. Columns (1)-(3) report estimates for the patent scope as the independent variable. The magnitudes of estimated coefficients range between 0.712 (without fixed effects), to 0.735 (with fixed effects). All coefficients are significant at the $1 \%$ level. We interpret these results as a 0.735 increase in log-odds of the patent being disclosed in a specific disclosure for every additional 4-digit IPC technology class it is assigned to. Columns (4)-(6), (7)-(9) and (10)-(12) report results for number of claims, patent originality and INPADOC family size as dependent variables, respectively. We find these coefficients to be significant at the $1 \%$ level. Log-odds of the patent being disclosed in a specific disclosure increase by 0.0137 for every additional patent claim it has, 3.952 for a unit increase in patent originality (which represents the whole range for this variable) and 0.0045 for each additional patent family member.

\section{[Table 4 about here.]}

Positive and statistically significant effects of patent quality measures on the likelihood of those patents being disclosed in a specific disclosure support our Hypothesis 2. The coefficients on the patent quality measures of scope, family size, number of claims, number of patent references, number of non-patentliterature references and originality are all positive and significant, implying that higher quality patents are indeed more likely to be disclosed to SSOs via specific disclosures.

For robustness, we also run additional OLS models replicating the analysis from Panels A and B of Table 4. We use the same dependent variable, and include both year and SSO fixed effects. All estimated coefficients remain positive and significant. 


\subsection{Disclosure Preferences Across the Value Chain}

\subsubsection{Variables}

Next, to test if the large, downstream firms are more likely to use generic disclosures, we first need to determine if firms who disclose patents to standards have a downstream presence in the area of those standards. For example, if a firm makes a patent disclosure to the $3 \mathrm{G}$ wireless standard, while it contemporaneously manufactures 3G based products like cellular phones, then that firm is also downstream relative to $3 G$ standard. This analysis requires us to make a link between industry segments, technical standards and firm activities.

To link standards with relevant industries, we use all specifically disclosed patents to create a list of standard-relevant IPC codes, and link those to NAICS industry codes. Past studies have generally linked patent classes to relevant industries by using one of the two publicly available patent-to-industry concordances. The first one is Yale Technology Concordance (YTC), originally developed by Evenson et al. [1991], and the second one is Brian Silverman's Technology Concordance described in Silverman [1999]. Both of these concordances are probabilistic links of patent technology classes to industry codes based on a set of Canadian patents which were assigned industry codes in the early 1990s. Unfortunately, because these concordances are based on 1990s industry codes, some of the important new industries-like wireless communications—are largely absent.

To get around this problem, we use a newly developed patent-industry concordance using the Algorithmic Links with Probabilities (ALP) approach [Lybbert and Zolas, 2014]. This approach exploits recent advances in text analysis and relies on a keyword extraction from the patents themselves and subsequent probabilistic matching to textual descriptions of technology, industry or trade classifications. To generate the concordance, Lybbert and Zolas [2014] use the full PATSTAT database from the European Patent Office (EPO), and arrive at two-way probability distributions of 1) the IPC technology classes used within each industry and 2) industries using certain types of IPC technology classes. ${ }^{29}$

Before we apply the ALP concordance, we create lists of all 4-digit IPC technology codes relevant to each individual standard by using specifically disclosed patents. We then match those IPC codes to NAICS codes obtained from the ALP concordance dataset. ${ }^{30}$ Once we generate a map of NAICS codes for each standard, we resort to S\&P Compustat Historical Segment data for each firm making a disclosure. Historical segment NAICS codes are compared to the lists of standard-relevant NAICS codes, and those firms whose historical NAICS codes match any of standard-relevant NAICS codes are labeled as downstream to that particular

\footnotetext{
${ }^{29}$ Lybbert and Zolas [2014] concordance is available from the World Intellectual Property Organization (WIPO) at: http://www.wipo.int/export/sites/www/econ_stat/en/economics/zip/wp14_concordance.zip [last accessed: 06/10/2015].

${ }^{30}$ While we generate frequency weights for IPC-standard lists, we do not use them in the final analysis as to not overcomplicate the process. Rather, we use a simple discrete measure of "match" or "no-match".
} 
standard. For example, if firms 1 and 2 disclose patents to standard A, and the ALP concordance results in that standard A being associated with NAICS codes $X$ and $Y$, then if firm 1's historical NAICS code is $X$ at the time of its disclosure, and firm 2's historical NAICS code is Z at the time of its disclosure, firm 1 will be labeled as downstream and firm 2 will be labelled as upstream. In addition, since they are not listed in Compustat, we manually classify all universities and research institutes as upstream entities.

Counting disclosures can also be tricky. For example, a single specific declaration letter can disclose multiple patents to multiple standards, while a generic declaration can disclose potentially many patents to one or more standards. To compare disclosure preference across different entities, we count multiple patents disclosed to the same standard by the same firm in the same year as a single disclosure. In other words, even if firm 1 was to disclose 10 patents to standard A in 5 different specific disclosures during the course of one year, we would count this as a single specific disclosure made by firm 1 to standard A in that year. To reduce sample variability and ensure consistent comparison across firms and standards, we analyze only those standards receiving both specific and generic disclosures in a given year. Standards receiving only specific or only generic disclosures are dropped from the sample. This results in a final sample of 840 firm-standard-year triplets in which a disclosure took place.

Since our hypothesis contends that the total profitability of downstream firms will increase the likelihood of these firms to utilize generic disclosures, we need to account for firm total profitability in the analysis. While various different financial and operational proxies have been used in the past, we use total revenue, ${ }^{31}$ as we feel this measure of output is the most closely aligned with the model and our downstream size parameter $\theta_{i}$. For this total profitability measure, we calculate the logarithm of the average revenues over a three year window (from the year of disclosure to two years prior). ${ }^{32}$ Table 5 provides more detailed descriptions of variables used in this part of the analysis.

[Table 5 about here.]

Summary statistics are reported in Table 6.

[Table 6 about here.]

\subsubsection{Specification}

To test if large, downstream firms are more likely to use generic disclosures, we use logit regressions:

\footnotetext{
${ }^{31}$ For robustness, we also run separate analyses where we use operating profits (EBIT) and net income as proxies for firm total profitability. Although the coefficients estimated in these analyses have the same signs as those estimated in our main specification, they are generally not as significant.

${ }^{32}$ Our results are robust to changes in time-window length.
} 


$$
\operatorname{Pr}\left(\operatorname{Spec}_{i, s, t}=1\right)=F\left(\alpha+\beta \times D_{i, s, t}+\gamma \times R_{i, t}+\delta \times D_{i, s, t} \times R_{i, t}+\operatorname{Ind}_{i}+\text { Year }_{t}+S S O_{s}+\epsilon_{i, s, t}\right)
$$

where

$$
F(z)=\frac{e^{z}}{\left(1+e^{z}\right)}
$$

In this specification, the dependent variable $S p e c_{i, s, t}$ is a dummy equal to 1 if a specific disclosure was made by the firm $i$ to a standard $s$ in a year $t$. $D_{i, s, t}$ is a dummy equal to 1 if the firm $i$ was determined to be downstream to a standard $s$ in a year $t . R_{i, t}$ represents average revenues in 3-year window prior to the disclosure for the firm $i$ in a year $t$. Ind $i$ is industry sector fixed effect (4-digit SIC level), Year $m$ is a year fixed effect and $\mathrm{SSO}_{S}$ is SSO fixed effect. We are particularly interested in the sign of $\delta$ coefficient on the interaction term of the downstream dummy and firm size proxy. A negative $\delta$ would indicate that for downstream firms, an increase in firm size measure $R_{i, t}$ would reduce the probability of making a specific disclosure.

\subsubsection{Results}

Table 7 reports the results, and shows that an increase in firm size leads to a reduced probability of specific disclosure for downstream firms. We include the results with and without year, SSO and industry fixed effects, and report robust standard errors. The binary dependent variable Specific Disclosure is coded as one if the disclosure was a specific disclosure, and zero otherwise.

The interaction between the downstream dummy and the proxy for firm size is consistently negative and statistically significant. We focus our discussion on Column (6), which reports estimates when year, SSO and industry fixed effects are all accounted for. In this specification, independent variables are Downstream Presence, which is coded as one of the entity has downstream presence relative to the standard in a given year in the sample, Total Revenues, which is a proxy for firm size and represents a logged mean of disclosing entity's total revenues in the 3-year window prior to the disclosure being made, and Downstream $x$ Total Revenue which is interaction of the two. In Column (6), Downstream Presence coefficient is positive and significant at the $10 \%$ level. The sign and magnitude of this coefficient imply that a firm being downstream relative to the standard increases log-odds of specific disclosure by 0.153 . The effect of firm size proxied by Total Revenues is negative, and not statistically significant. The interaction effect Downstream $x$ Total Revenue is negative and significant at the $10 \%$ level. The size of the interaction coefficient implies that an order of magnitude increase in the mean of disclosing entity's total revenues in the 3-year window prior to the disclosure being made leads to 0.114 decrease in log-odds of specific disclosure for downstream firms. 
[Table 7 about here.]

For robustness, we also run additional OLS models replicating the analysis from Table 7. We use the same dependent variable and include year, SSO and industry fixed-effects. Signs and significance of estimated coefficients do not change.

One natural concern is that downstream firms could simply have patents of lower-quality than those of upstream firms (for instance, they may stumble on "low-hanging fruits" in the process of improving the implementation of the standard). These quality differences may affect the results. To examine this, we calculated patent portfolio quality measures for all firms and all years in our sample, and merged them with the SSO disclosure data. We then averaged all the patent portfolio quality measures for all the upstream firms and the downstream firms for each standard (i.e., we separately calculated average patent quality measures for each standard within every SSO in our sample). We then ran t-tests comparing mean patent quality measures for the downstream and upstream firms. The results showed that there were no statistically significant differences between the upstream and downstream in the measures of scope, family size, patent references, and the truncation-corrected forward citation count. We did find, however, that the upstream firms had significantly more claims and non-patent references. These results helped allay concerns that the disclosure behavior of downstream firms was driven by differences in patent quality.

\section{Conclusion}

Technological standards are a central component of the modern network economy. Standard setting organizations play a variety of roles, one of the critical ones is ensuring the disclosure of relevant IP-in particular, potentially essential patents-prior to the key decisions regarding a proposed standard.

This paper analyzes disclosure and selection mechanisms in standard-setting and highlights several theoretical insights. The first one is that firms with stronger downstream presence are more likely to opt for a generic disclosure. The second one is that a generic disclosure corresponds on average to lower quality patents. In addition, the optimal FRAND system involves either all firms licensing patents at a single price (thus with no distinction between firms making generic and specific disclosures), or more generally compressing the range of rewards for these two classes of disclosures.

An illustrative empirical analysis is then undertaken to examine the first two insights. Using a handcollected data set, we find strong support for the contentions that large, downstream firms are more likely to make generic disclosures to SSOs and that higher quality patents are more likely to be disclosed via specific disclosures. 
At the same time, we are keenly aware that both the theoretical and empirical analyses do not capture the richness and complexity of this setting. Fortunately, this work suggests a number of avenues for future research. As we highlighted in Section 2.2.3, there are subtle but important differences in disclosure requirements across different SSOs. The first of these future directions is a need for a deeper understanding of the nature of disclosures to SSOs, which are a complex and little documented part of the standardization process. A better understanding of when and what firms choose to disclose, how these disclosures are interpreted, and how the commitments evolve over time would be very important for optimal policy setting. It would also be valuable to better understand the dynamics of technology push and market pull in the standardization process, a question not addressed in this paper.

Another important question is the interaction between disclosure requirements and forum-shopping. ${ }^{33}$ To what extent do disclosure requirements drive firms away from certain SSOs? Finally, the interviews suggest a complex set of interactions between formal and real authority in SSOs, which reflects the fact that many of the same firms interact across different standardization projects and different SSOs. The extent to which informal SSO practices affect firm behavior represents yet another important avenue for future research.

\footnotetext{
${ }^{33}$ As in Lerner and Tirole [2006], for example.
} 


\section{References}

Robert Axelrod, Will Mitchell, Robert E. Thomas, D. Scott Bennett, and Erhard Bruderer. Coalition Formation in Standard-Setting Alliances. Management Science, 41(9):1493-1508, 1995.

Rudi Bekkers and Andrew Updegrove. A Study of IPR Policies and Practices of a Representative Group of Standards Setting Organizations Worldwide. Technical report, US National Academies of Science, Board of Science, Technology, and Economic Policy (STEP), Project on Intellectual Property Management in standard-setting processes, 2012.

Rudi Bekkers, Christian Catalini, Arianna Martinelli, Timothy Simcoe, and Cesare Righi. Intellectual Property Disclosure in Standards Development. Proceedings from NBER conference on Standards, Patents $\mathcal{E}$ Innovation, Tucson (AZ), January 20 and 21, Tucson (AZ), January 20 and 21, 2012.

Lee Branstetter and Yoshiaki Ogura. Is Academic Science Driving a Surge in Industrial Innovation? Evidence from Patent Citations. Working Paper 11561, National Bureau of Economic Research, August 2005.

Bruno Cassiman, Reinhilde Veugelers, and Pluvia Zuniga. In Search of Performance Effects of (In)direct Industry Science Links. Industrial and Corporate Change, 17(4):611-646, 2008.

Robert E. Evenson, Jonathan Putnam, and Samuel Kortum. Estimating Patent Counts by Industry Using the Yale-Canada Concordance. Technical report, The National Science Foundation, 1991.

Joseph Farrell, John Hayes, Carl Shapiro, and Theresa Sullivan. Standard Setting, Patents and Hold-Up. Antitrust Law Journal, 74(3):603-671, 2007.

Bronwyn H. Hall and Manuel Trajtenberg. Uncovering GPTs with Patent Data. Working Paper 10901, National Bureau of Economic Research, November 2004.

Bronwyn H. Hall, Adam B. Jaffe, and Manuel Trajtenberg. The NBER Patent Citation Data File: Lessons, Insights and Methodological Tools. In Adam B. Jaffe and Manuel Trajtenberg, editors, Patents, Citations and Innovations: A Window on the Knowledge Economy, pages 403 - 459. The MIT Press, 2002.

Dietmar Harhoff, Frederic M. Scherer, and Katrin Vopel. Citations, Family Size, Opposition and the Value of Patent Rights. Research Policy, 32(8):1343 - 1363, 2003.

Jean O. Lanjouw and Mark Schankerman. Characteristics of Patent Litigation: A Window on Competition. The RAND Journal of Economics, 32(1):129-151, 2001.

Jean O. Lanjouw and Mark Schankerman. Patent Quality and Research Productivity: Measuring Innovation with Multiple Indicators. The Economic Journal, 114(495):441-465, 2004.

Jean O. Lanjouw, Ariel Pakes, and Jonathan Putnam. How to Count Patents and Value Intellectual Property: The Uses of Patent Renewal and Application Data. The Journal of Industrial Economics, 46(4):405-432, 1998.

Mark Lemley and Carl Shapiro. A Simple Approach to Setting Reasonable Royalties for Standard-Essential Patents. Berkeley Technology Law Journal, 28(2):1135-1166, 2013.

Josh Lerner. The Importance of Patent Scope: An Empirical Analysis. The RAND Journal of Economics, 25(2): 319-333, 1994.

Josh Lerner and Jean Tirole. A Model of Forum Shopping. American Economic Review, 96(4):1091-1113, 2006.

Josh Lerner and Jean Tirole. A Better Route to Tech Standards. Science, 343(6174):972-973, 2014.

Josh Lerner and Jean Tirole. Standard-Essential Patents. Journal of Political Economy, 123(3):547-586, 2015.

Travis J. Lybbert and Nikolas J. Zolas. Getting Patents and Economic Data to Speak to Each Other: An "Algorithmic Links with Probabilities" Approach for Joint Analyses of Patenting and Economic Activity. Research Policy, 43(3):530 - 542, 2014. 
Jonathan Putnam. The Value of International Patent Protection. Phd dissertation, Yale University, 1996.

Brian S. Silverman. Technological Resources and the Direction of Corporate Diversification: Toward an Integration of the Resource-Based View and Transaction Cost Economics. Management Science, 45(8): 1109-1124, 1999.

Timothy S. Simcoe. Standard Setting Committees: Consensus Governance for Shared Technology Platforms. American Economic Review, 102(1):305-36, 2012.

Timothy S. Simcoe, Stuart J. H. Graham, and Maryann P. Feldman. Competing on Standards? Entrepreneurship, Intellectual Property, and Platform Technologies. Journal of Economics E Management Strategy, 18(3): 775-816, 2009.

Robert M Townsend. Optimal Contracts and Competitive Markets with Costly State Verification. Journal of Economic Theory, 21(2):265 - 293, 1979.

Manuel Trajtenberg. A Penny for Your Quotes: Patent Citations and the Value of Innovations. The RAND Journal of Economics, 21(1):172-187, 1990.

Manuel Trajtenberg, Rebecca Henderson, and Adam B. Jaffe. University Versus Corporate Patents: A Window On The Basicness Of Invention. Economics of Innovation and New Technology, 5(1):19-50, 1997.

E. Glen Weyl and Michal Fabinger. Pass-Through as an Economic Tool: Principles of Incidence under Imperfect Competition. Journal of Political Economy, 121(3):528-583, 2013. 
Tables 
Table 1: Summary of Patent Disclosures

\begin{tabular}{cccccccc}
\hline \hline Disclosure Type & Standards & Declarations & $\begin{array}{c}\text { Patent-Standard } \\
\text { Pairs }\end{array}$ & $\begin{array}{c}\text { All U.S. Patents } \\
\text { Disclosed }\end{array}$ & $\begin{array}{c}\text { Associated Patent } \\
\text { Pools }\end{array}$ & $\begin{array}{c}\text { Entities } \\
\text { Represented }\end{array}$ & $\begin{array}{c}\text { Manufacturers } \\
\text { Generic }\end{array}$ \\
Specific & 1,082 & 2,498 & - & 285,972 & 17 & 353 & 174 \\
\hline \hline
\end{tabular}

Notes. The table summarizes the disclosures received in the sample. Standards indicates the number of different standard projects in the sample where disclosures of each type were made. Declarations indicates the number of distinct documents disclosing patent holdings made to the standards. Patent-Standard Pairs represents the number of distinct disclosed patent-standard pairs. All U.S. Patents Disclosed is the number of unique patents disclosed across all standards (the procedure for identifying patents disclosed in generic disclosures and narrowing down the number of identified patents to standard-relevant ones is discussed in the text). Associated Patent Pools is the number of patents patent pools related to the standards in the sample. Entities Represented is the number of different entities in the sample where disclosures of each type were made. Manufacturers is the subset of these entities having a primary SIC code between 2000 and 3999.

Table 2: Summary of Patent Disclosures by SSO

\begin{tabular}{|c|c|c|c|c|c|c|c|}
\hline Disclosure Type & SSO & Declarations & $\begin{array}{c}\text { Patent-Standard } \\
\text { Pairs }\end{array}$ & $\begin{array}{l}\text { U.S. Patents } \\
\text { Disclosed }\end{array}$ & $\begin{array}{c}\text { Associated Patent } \\
\text { Pools }\end{array}$ & $\begin{array}{c}\text { Entities } \\
\text { Represented }\end{array}$ & Manufacturers \\
\hline \multirow{7}{*}{ Generic } & ANSI & 542 & - & 42,695 & 5 & 94 & 55 \\
\hline & ATSC & 36 & - & 4,878 & 1 & 24 & 14 \\
\hline & ETSI & 501 & - & 15,603 & 2 & 23 & 11 \\
\hline & IEC & 420 & - & 20,804 & 7 & 139 & 77 \\
\hline & IEEE & 671 & - & 80,907 & 1 & 160 & 79 \\
\hline & ISO & 313 & - & 45,510 & 8 & 75 & 38 \\
\hline & $I T U$ & 15 & - & 391 & 4 & 4 & 3 \\
\hline \multirow{7}{*}{ Specific } & ANSI & 150 & 449 & 263 & 0 & 74 & 42 \\
\hline & ATSC & 22 & 432 & 409 & 1 & 18 & 11 \\
\hline & ETSI & 1216 & 23661 & 5711 & 4 & 94 & 46 \\
\hline & $I E C$ & 721 & 465 & 294 & 7 & 63 & 37 \\
\hline & IEEE & 259 & 921 & 634 & 1 & 101 & 57 \\
\hline & ISO & 220 & 475 & 275 & 10 & 67 & 39 \\
\hline & $I T U$ & 295 & 610 & 351 & 6 & 78 & 40 \\
\hline
\end{tabular}

Notes. The table summarizes the disclosures received, broken down by the seven SSOs in the sample. Standards indicates the number of different standard projects in the sample where disclosures of each type were made. Declarations indicates the number of distinct documents disclosing patent holdings made to the standards. Patent-Standard Pairs represents the number of distinct disclosed patent-standard pairs. U.S. Patents Disclosed is the number of unique patents disclosed across all standards (the procedure for identifying patents disclosed in generic disclosures and narrowing down the number of identified patents to standard-relevant ones is discussed in the text). Associated Patent Pools is the number of patents patent pools related to the standards in the sample. Entities Represented is the number of different entities in the sample where disclosures of each type were made. Manufacturers is the subset of these entities having a primary SIC code between 2000 and 3999. 
Table 3: Patent Quality Analysis - Summary Statistics

\begin{tabular}{|c|c|c|c|c|c|}
\hline Variables & $\mathrm{N}$ & mean & sd & $\min$ & $\max$ \\
\hline Specific Disclosure & 63765 & 0.08233 & 0.27487 & 0 & 1 \\
\hline Forward Citations (Truncated) & 63765 & 1.22786 & 1.62564 & 0 & 46.24749 \\
\hline Patent Scope & 63765 & 1.58625 & 0.91639 & 1 & 12 \\
\hline Number of Claims & 63750 & 19.13075 & 13.83417 & 1 & 269 \\
\hline Patent Originality & 63765 & 0.50233 & 0.25746 & 0 & 0.94690 \\
\hline Number of Patent References & 63765 & 14.71550 & 28.41547 & 1 & 841 \\
\hline Number of Non-Patent Refences & 63765 & 3.42933 & 11.47524 & 0 & 455 \\
\hline INPADOC Family Size & 63765 & 4.67264 & 19.55966 & 1 & 934 \\
\hline
\end{tabular}

Notes. The unit of observation is each U.S. patent disclosed to the standards in the sample. We limit our analysis to only those standards receiving both specific and generic patent disclosures, resulting in 63,765 observations. Specific Disclosure is coded as one if the patent is disclosed to a standard in a specific disclosure, and zero otherwise. Forward Citations (Truncated) is the truncation-corrected number of forward citations to the patent through the end of 2013. Patent Scope is defined in the text and follows Lerner [1994]. Number of Claims is the count of claims in the patent. Patent Originality is defined in the text and follows Hall et al. [2002]. Number of Patent References is the number of U.S. patents cited (backward citations) in the disclosed patents. Number of Non-Patent Patent References is the number of other prior art (scientific articles, for example) cited in the disclosed patents. INPADOC Family Size is the number of countries-patents of the patent family. 
Table 4: Patent Quality Results - Dependent Variable is Specific Disclosure

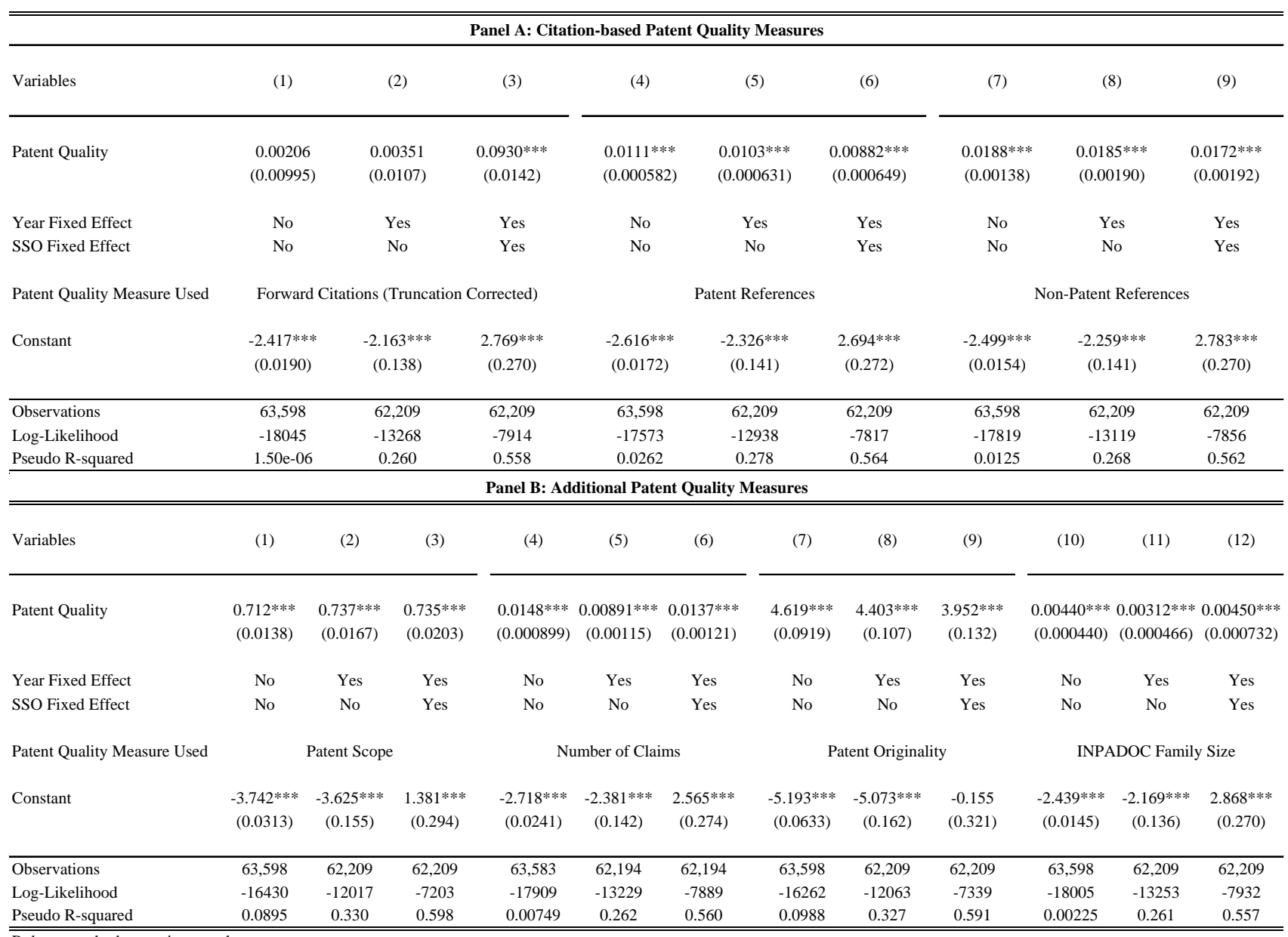

Robust standard errors in parentheses

*** $\mathrm{p}<0.01$, ** $\mathrm{p}<0.05,{ }^{*} \mathrm{p}<0.1$

Notes. The right-hand side variable-Specific Disclosure-is coded as one if the patent is disclosed in a specific disclosure; and zero otherwise. The unit of observation is each patent-standard pair among the patent disclosures in the sample. The regressions employ a logit specification. Some regressions include fixed effects for the year of the first disclosure of the patent to the standard and the SSO. Panel A regressions use citation-based patent quality measures as dependent variables. Panel $B$ regressions use other patent quality measures as dependent variables. All seven measures of patent quality employed are defined in the text and Table 3. 
Table 5: Disclosure Preference Analysis - Variable Descriptions

Variables

Downstream Presence

Specific Disclosure

Year Disclosed

Total Revenues (Logged 3-year Average)
Description

Dummy equal to 1 if a disclosure was specific; 0 otherwise

Dummy equal to 1 if the firm has downstream presence; 0 otherwise

Year in which a disclosure was made

Logged Mean Total Revenue in a 3-yr time window before the disclosure

Table 6: Disclosure Preference Analysis - Summary Statistics

\begin{tabular}{|c|c|c|c|c|c|}
\hline Variables & $\mathrm{N}$ & mean & sd & $\min$ & $\max$ \\
\hline Downstream Presence & 831 & 0.7340554 & 0.442101 & 0 & 1 \\
\hline Specific Disclosure & 831 & 0.3670277 & 0.4822844 & 0 & 1 \\
\hline Year Disclosed & 831 & 2003.207 & 5.614568 & 1986 & 2013 \\
\hline Total Revenues (Logged 3-year Average) & 817 & 10.17032 & 3.00216 & 0.0497421 & 18.84476 \\
\hline
\end{tabular}

Notes. The unit of observation is each disclosure made to the standard in a given year in the sample. We limit our analysis to only those standards receiving both specific and generic patent disclosures, resulting in 831 observations. Downstream Presence is coded as one if the entity has downstream presence relative to the standard, and zero otherwise. Specific Disclosure is coded as 1 if the disclosure was specific, and zero otherwise. Year Disclosed represents the year in which the disclosure to the standard was made. Total Revenues represents a logged mean of disclosing entity's total revenues in the 3-year window prior to the disclosure being made. 
Table 7: Disclosure Type Results - Dependent Variable is Specific Disclosure

\begin{tabular}{|c|c|c|c|c|c|c|}
\hline Variables & (1) & $(2)$ & (3) & (4) & (5) & (6) \\
\hline Downstream Presence & $\begin{array}{l}-0.207 \\
(0.161)\end{array}$ & $\begin{array}{l}-0.263 \\
(0.168)\end{array}$ & $\begin{array}{c}1.441^{* *} \\
(0.605)\end{array}$ & $\begin{array}{l}1.192^{*} \\
(0.675)\end{array}$ & $\begin{array}{l}1.362 * \\
(0.721)\end{array}$ & $\begin{array}{l}1.233^{*} \\
(0.750)\end{array}$ \\
\hline Total Revenue (Logged 3-year Average) & & $\begin{array}{c}-0.0997^{* * *} \\
(0.0268)\end{array}$ & $\begin{array}{c}0.0128 \\
(0.0451)\end{array}$ & $\begin{array}{c}0.0396 \\
(0.0535)\end{array}$ & $\begin{array}{c}0.0533 \\
(0.0568)\end{array}$ & $\begin{array}{l}-0.0125 \\
(0.0613)\end{array}$ \\
\hline Downstream x Total Revenue & & & $\begin{array}{c}-0.168^{* * *} \\
(0.0576)\end{array}$ & $\begin{array}{l}-0.140^{* *} \\
(0.0626)\end{array}$ & $\begin{array}{l}-0.160 * * \\
(0.0665)\end{array}$ & $\begin{array}{c}-0.114 * \\
(0.0687)\end{array}$ \\
\hline Year Fixed Effect & No & No & No & Yes & Yes & Yes \\
\hline SSO Fixed Effect & No & No & No & No & Yes & Yes \\
\hline Industry Fixed Effect (4-digit SIC) & No & No & No & No & No & Yes \\
\hline Constant & $\begin{array}{c}-0.394 * * * \\
(0.137)\end{array}$ & $\begin{array}{c}0.639^{* *} \\
(0.307)\end{array}$ & $\begin{array}{l}-0.528 \\
(0.493)\end{array}$ & $\begin{array}{l}0.0118 \\
(1.854)\end{array}$ & $\begin{array}{c}0.546 \\
(1.908)\end{array}$ & $\begin{array}{c}1.567 \\
(1.427)\end{array}$ \\
\hline Observations & 831 & 817 & 817 & 805 & 805 & 799 \\
\hline Log-Likelihood & -545.4 & -527.1 & -522.3 & -472.7 & -462.1 & -430 \\
\hline Pseudo R-squared & 0.00150 & 0.0167 & 0.0256 & 0.109 & 0.129 & 0.183 \\
\hline
\end{tabular}

Robust standard errors in parentheses

*** $\mathrm{p}<0.01,{ }^{* *} \mathrm{p}<0.05,{ }^{*} \mathrm{p}<0.1$

Notes. The right-hand side variable-Specific Disclosure-is coded as 1 if the disclosure was specific, and zero otherwise. The unit of observation is each disclosure made to the standard in a given year in the sample. We limit our analysis to only those standards receiving both specific and generic patent disclosures, resulting in 831 observations. Downstream Presence is coded as one if the entity has downstream presence relative to the standard, and zero otherwise. Year Disclosed represents the year in which the disclosure to the standard was made. Total Revenues represents a logged mean of disclosing entity's total revenues in the 3-year window prior to the disclosure being made. 